\title{
HIF2A gain-of-function mutations detected in duodenal gangliocytic paraganglioma
}

\section{Dear Editor,}

Somatic hypoxia-inducible factor 2 alpha (HIF2A) mutations are responsible for a newly discovered syndrome of multiple paragangliomas (PGL) and duodenal somatostatinomas associated with polycythemia (Pacak-Zhuang syndrome) (Zhuang et al. 2012, Pacak et al. 2013, Toyoda et al. 2014). In this syndrome, found exclusively in females, somatostatinomas are located in the 2 nd portion of the duodenum.

Gangliocytic PGL (GPGL), a mixed neuroectodermalendodermal tumor, is a rare and unique type of PGL that is almost exclusively located in the 2 nd portion of the duodenum, much like HIF2A-related somatostatinomas. Both GPGLs and HIF2A-related somatostatinomas produce and/or secrete somatostatin. Clinically, GPGL patients often present with gastrointestinal bleeding, iron deficiency anemia, abdominal pain, and weight loss. Despite their clinical presentation, signs and symptoms of catecholamine excess are not present, because these tumors do not produce catecholamines due to the absence of tyrosine hydroxylase, a rate-limiting enzyme in catecholamine biosynthesis. Until now, no familial cases of GPGL have been described.

Gain-of-function somatic HIF2A mutations in patients (with this syndrome or without it) are located close to the oxygen-dependent degradation domain (ODD) of HIF2 $\alpha$ (Zhuang et al. 2012, Comino-Mendez et al. 2013, Pacak et al. 2013, Toledo et al. 2013). The mutated HIF $2 \alpha$ protein prevents proper hydroxylation by prolyl hydroxylases, resulting in abnormally low binding to the von Hippel-Lindau (VHL) protein and enhances HIF2 $\alpha$ stabilization and activation. Consequently, the HIF2 $\alpha$ downstream genes, including the cancer signaling pathway genes, are upregulated, contributing to the pathogenesis of cancer. This notion was nicely presented in a study of Toledo et al., where HIF2 $\alpha$ mutants in HEK293, renal cell carcinoma 786-0, or rat pheochromocytoma PC12 cell lines, showed increased stability, resistance to
VHL-mediated degradation, target induction, and reduced chromaffin cell differentiation (Toledo et al. 2013). Moreover, mice injected with mutant HIF2A tumor cells developed tumors with a shorter latency than tumors in mice injected with wildtype (WT) HIF2A tumor cells. As concluded by the authors, these results further support a direct oncogenic role for somatic gainof-function HIF $2 A$ mutations in human neoplasia and strengthen the link between hypoxic pathways and PGL.

We tested whether duodenal GPGLs share a similar pathogenic mechanism with PGLs associated with somatic HIF2A mutations. Ten GPGL tissues (Fig. 1A-D) were screened for somatic HIF $2 A$ mutations; patient 1 was also tested for a potential germline HIF2A mutation, which included blood leukocytes and gallbladder tissue. Genomic DNA was extracted from paraffin-embedded tissue and white blood cells using a DNeasy Blood \& Tissue Kit (Qiagen). Two female patients were found to have pathogenic somatic HIF2A mutations in their GPGLs. No HIF2A mutation was found in the blood or gallbladder tissue of patient 1 . In patient 1 (a 54-year-old woman), a periampullar GPGL (Fig. 1E) was found to have a C $\alpha \mathrm{T}$ substitution at base 1556 in exon 12 of HIF2A. In patient 2 (a 46-year-old woman), a periampullar GPGL (Fig. 1E) exhibited a CoT substitution at base 1630 of the same exon. The mutations resulted in amino acid substitutions in HIF2 $\alpha$ protein to T519M and P544S, respectively. Alignment of multiple HIF2 $\alpha$ peptide sequences indicated that both amino acids are located in the proximal region of the primary hydroxylation site of HIF2 $\alpha$ protein and are evolutionary conserved across different species (Fig. 1F). Both mutations were closely located to the oxygen-sensing domain of HIF2 $\alpha$, which affects its protein ubiquitination in the presence of oxygen.

To understand the functional impact of either mutation, we obtained a pcDNA3-HA-HIF2 $\alpha$ plasmid containing human HIF2A coding sequence (Addgene plasmid 18950) and introduced $\mathrm{T} 519 \mathrm{M}$ and P544S mutations through Quikchange Lightning Site-directed

Published by Bioscientifica Ltd 
A
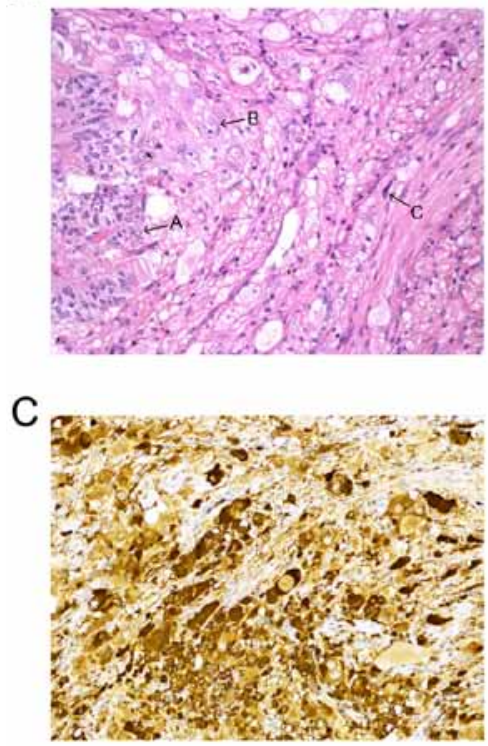

E

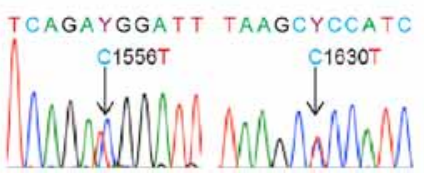

B

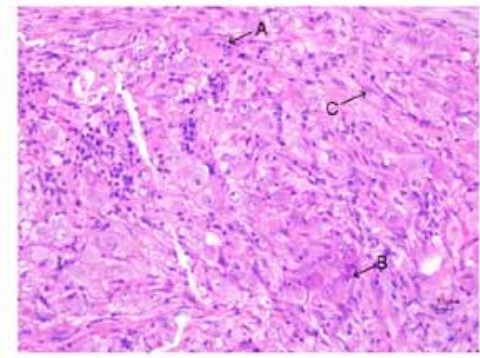

D .

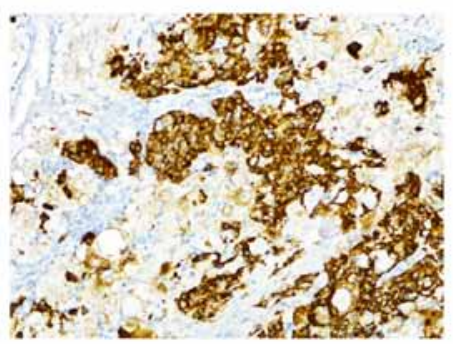

F

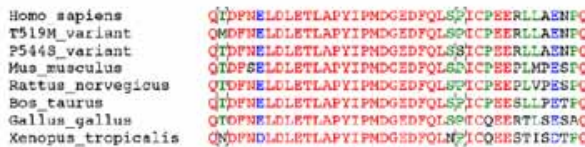

\section{Figure 1}

Histopathological features of GPGLs from patient 1 (A) and patient 2 (B). In both tumors, the neoplastic cells were arranged in solid nests, trabeculae, and fascicules with areas of epithelioid (arrow A), ganglion-like (arrow B), and spindle (arrow C) cells. Hematoxylin \& eosin stain, magnification $\times 20$. Positive immunohistochemical stains for chromogranin A (C) and somatostatin (D) in the tumor from patient 1, magnification $\times 20$. Both GPGLs were negative for tyrosine hydroxylase (ImmunoStar) immunohistochemistry (data not shown). (E) Genomic DNA sequencing of HIF2A exon 12 nucleotides 1551-1561. Heterozygous T519M (patient 1) and P544S (patient 2) somatic mutations were identified in both GPGLS. No HIF2A mutations were found in the blood or gallbladder tissue of patient 1. (F) Alignment of amino acid sequence of HIF $2 \alpha$ residues 1625-1635 in humans, mice, rats, ox, chickens, and frogs.
Mutagenesis Kit (Agilent). The plasmids were introduced into HEK293 cells with Lipofectamine 2000 (Invitrogen) for detection of HIF2 $\alpha$ ubiquitination and measurement of protein half-lives.

Through an immunoprecipitation assay, we found that the ubiquitination of HIF2 $\alpha$ was reduced in either the T519M or P544S HIF2 $\alpha$ variant compared with WT protein, with a reduction of 35.16 and $61.76 \%$, respectively (Fig. 2A). We confirmed the changes in protein stability of the mutant HIF $2 \alpha$ via a cycloheximide (CHX) chase assay. WT HIF $2 \alpha$ protein exhibited a halflife of $7.60 \mathrm{~min}$, suggesting rapid turnover of HIF $2 \alpha$ protein under normoxic conditions. By contrast, T519M and P544S variants were more stable, with halflives extended to 67.21 and $81.09 \mathrm{~min}$, respectively, when compared with WT protein with a half-life of 7.6 min (Fig. 2B and C). Furthermore, the expression of canonical hypoxia-related genes in tumors was measured through quantitative real-time PCR (Fig. 2D). We identified the upregulation of genes downstream of HIF2 $\alpha$, including EDN1, EPO, GLUT1, GNA14, LDHA, and VEGFA measured through a real-time PCR assay on a ViiA 7 real-time PCR system (Applied Biosystems).

Until now, most GPGLs were considered sporadic, although some of them are found rarely in association with neurofibromatosis type 1 . This is the first report that shows that somatic gain-of-function HIF2A mutations are present in 20\% of GPGLs in the present series. The mutations appear to be located in the hot spot of the oxygen-sensing domain of HIF $2 \alpha$, resulting in increased HIF2 $\alpha$ stabilization and impaired ubiquitination and degradation, as also described in studies by Dahia et al. (2005), Toledo et al. (2013), and Comino-Mendez et al. (2013). Increased half-life of HIF2 $\alpha$ and enhanced activity trigger its downstream regulated genes and thus, the upregulation of the HIF signaling pathway, classifying these tumors as cluster 1. The evidence of HIF2A oncogenicity of PGLs was previously demonstrated by Dahia et al. (2005). The authors showed that HIF2A mutations conferred growth advantage (e.g., by resistance to VHL-mediated degradation, increased tumor cell stability, and reduced PC12 cell differentiation) in a mouse subcutaneously injected with various mutant HIF2A tumor cells.

The developmental origin of GPGL is currently unclear, but it is believed that this tumor derives from a defective sheet of intraembryonic endoderm progenitor cells (primordial gut; epithelial cells in GPGL), rests that have recruited progenitor cells of neuroectoderm, nerves/Schwann and ganglion cells (spindle cells and ganglion-like cells, respectively in GPGL), and smooth muscle (Perrone et al. 1985, Witzigmann et al.

Published by Bioscientifica Ltd. 


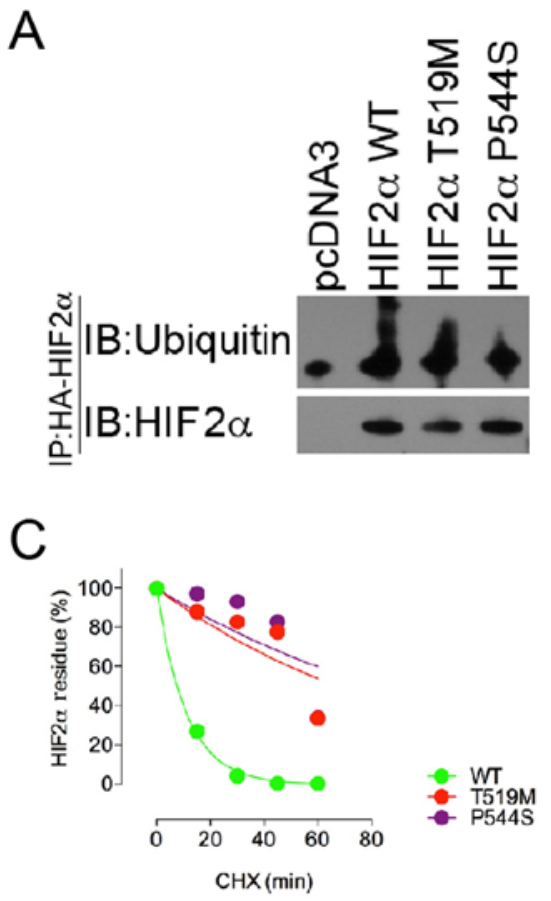

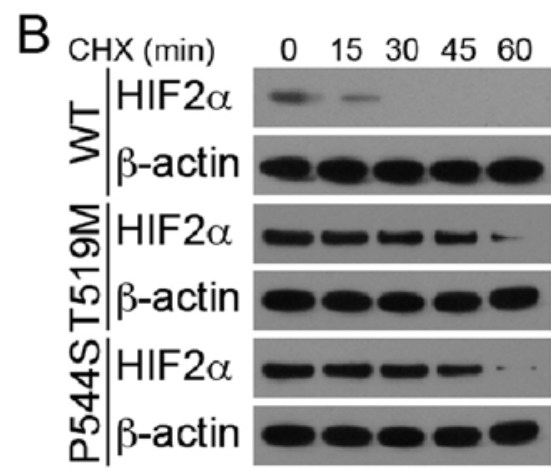
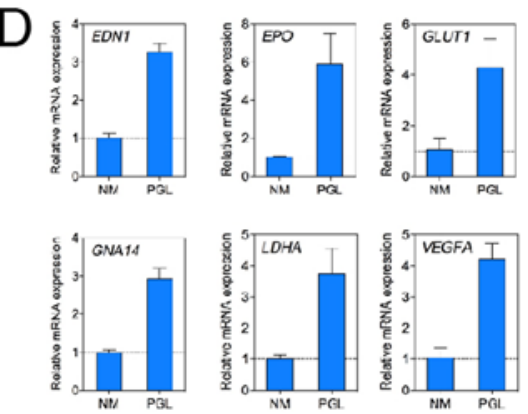

\section{Figure 2}

(A) Immunoprecipitation of HIF2 $\alpha$ ubiquitination. Recombinant HIF $2 \alpha$ protein was immunoprecipitated with an antibody against HA-tag. Protein ubiquitination was probed with a polyclonal antibody against ubiquitin. (B) $\mathrm{CHX}$ chase assay measurement of HIF $2 \alpha$ protein stability. (C) Quantification of HIF2 $\alpha$ protein stability on the basis of data shown in B. (D) Quantitative mRNA expression measurement of four hypoxia-related genes in tumor specimen from patient 1: EDN1, EPO, GLUT1, GNA14, LDHA, and VEGFA performed by quantitative PCR assay. A normal adrenal medulla (NM) specimen was used as a control.
2002). GPGLs are often positive for somatostatin, and both tumors are initially derived from endoderm, which is capable of recruiting neuroendocrine cells. Since somatic HIF2A mutations are found in both tumor types, we hypothesize that these mutations with HIF signaling pathway upregulation may affect common precursor cells and their differentiation to somatostatin-secreting endocrine cells. Therefore, some PGLs, somatostatinomas, and GPGLs share similarities in their pathogenic mechanisms.

Amino acid substitutions in the ODD domain have been linked to abnormalities in oxygendependent hydroxylation of HIF $2 \alpha$, as well as abnormal accumulation of HIF $2 \alpha$ protein under a normal oxygen level. Indeed, similar to previous findings related to HIF $2 \alpha$ stabilization and degradation, both mutations resulted in significant increased stability (half-lives extended to 67.21 and 81.09 min for T519M or P544S, respectively) and decreased protein ubiquitination (reduction of 35.16 and $61.76 \%$ for $\mathrm{T} 519 \mathrm{M}$ or $\mathrm{P} 544 \mathrm{~S}$, respectively). The results confirm that HIF $2 \alpha$ mutant protein found in both patients escaped from the degradation mechanism and likely induced a pseudohypoxic phenotype, as well as oncogenic gene transcription, through the canonical hypoxia pathway.

Moreover, mutated HIF2A overexpression could contribute to a more immature phenotype of GPGL since HIF2A knockdown in neuroblastomas, a tumor with similar developmental, biochemical, and localization characteristics as a PGL, promotes a sympathetic neuronal differentiation (Pietras et al. 2009). By contrast, high normoxic and hypoxic levels of HIF $2 \alpha$ protein in neuroblastoma cells are associated with immature recruitment of endothelial cells as well as a neural crestlike phenotype, all which resemble GPGL as an immature tumor (Pietras et al. 2009).

Whether HIF2A mutations may be associated with the presence of other (neuro)endocrine tumors or health-related abnormalities, especially in tumors that are found in the 2 nd portion of the duodenum apart from those associated with MEN1, NF1, and HIF2Arelated somatostatinomas, is currently unclear. If a HIF2A mutation is found, patients may be considered to have personalized clinical and therapeutic management with a HIF2 $\alpha$-targeted drug as for other hereditary neuroendocrine tumors undergoing various genetic screening, including next-generation sequencing (Neumann \& Eng 2009).

Zhengping Zhuang1,*
Chunzhang Yang2,*
Ales Ryska ${ }^{3}$
Yuan Ji $^{4}$
Yingyong Hou
Sky D Graybill
Petra Bullova
6,7

Published by Bioscientifica Ltd 
Irina A Lubensky ${ }^{8}$

Günter Klöppel ${ }^{9}$

Karel Pacak 6

1Surgical Neurology Branch, National Institute of Neurological Disorders and Stroke, National Institutes of Health, Bethesda, Maryland, USA

${ }^{2}$ Neuro-Oncology Branch, National Cancer Institute, National Institutes of Health, Bethesda, Maryland, USA

${ }^{3}$ The Fingerland Department of Pathology, Charles University Medical Faculty Hospital, Hradec Kralove, Czech Republic ${ }^{4}$ Department of Pathology, Zhongshan Hospital, Fudan University, Shanghai, China ${ }^{5}$ San Antonio Military Medical Center, Fort Sam Houston, Texas, USA ${ }^{6}$ Section on Medical Neuroendocrinology, Eunice Kennedy Shriver National Institute of Child Health and Human Development, National Institutes of Health, Bethesda, Maryland, USA

7 Department of Molecular Medicine, Institute of Virology, Slovak Academy of Sciences, Bratislava, Slovakia

${ }^{8}$ Cancer Diagnosis Program, Division of Cancer Treatment and Diagnosis, National Cancer Institute, National Institutes of Health, Bethesda, Maryland, USA

${ }^{9}$ Consultation Center for Pancreas and Neuroendocrine Tumors, Department of Pathology, Technical University Munich, Munich, Germany *(Zhengping Zhuang and Chunzhang Yang contributed equally to this work)

(Correspondence should be addressed to K Pacak; email: karel@mail.nih.gov)

\section{Declaration of interest}

The authors declare that there is no conflict of interest that could be perceived as prejudicing the impartiality of the research reported.

\section{Funding}

This work was supported by the Intramural Research Program of the Eunice Kennedy Shriver National Institute of Child Health and Human
Development and the National Institute of Neurological Disorders and Stroke, NIH.

\section{Acknowledgements}

The authors would like to acknowledge the technical assistance of Katherine Wolf in the production and editing of this manuscript.

\section{References}

Comino-Mendez I, de Cubas AA, Bernal C, Alvarez-Escola C, SanchezMalo C, Ramirez-Tortosa CL, Pedrinaci S, Rapizzi E, Ercolino T, Bernini G, et al. 2013 Tumoral EPAS1 (HIF2A) mutations explain sporadic pheochromocytoma and paraganglioma in the absence of erythrocytosis. Human Molecular Genetics 22 2169-2176. (doi:10.1093/hmg/ddt069)

Dahia PL, Ross KN, Wright ME, Hayashida CY, Santagata S, Barontini M, Kung AL, Sanso G, Powers JF, Tischler AS, et al. 2005 A HIF1alpha regulatory loop links hypoxia and mitochondrial signals in pheochromocytomas. PLoS Genetics 1 72-80. (doi:10.1371/journal. pgen.0010008)

Neumann HP \& Eng C 2009 The approach to the patient with paraganglioma. Journal of Clinical Endocrinology and Metabolism 94 2677-2683. (doi:10.1210/jc.2009-0496)

Pacak K, Jochmanova I, Prodanov T, Yang C, Merino MJ, Fojo T, Prchal JT, Tischler AS, Lechan RM \& Zhuang Z 2013 New syndrome of paraganglioma and somatostatinoma associated with polycythemia. Journal of Clinical Oncology 31 1690-1698. (doi:10.1200/JCO.2012.47.1912)

Perrone T, Sibley RK \& Rosai J 1985 Duodenal gangliocytic paraganglioma. An immunohistochemical and ultrastructural study and a hypothesis concerning its origin. American Journal of Surgical Pathology 9 31-41. (doi:10.1097/00000478-198501000-00007)

Pietras A, Hansford LM, Johnsson AS, Bridges E, Sjolund J, Gisselsson D, Rehn M, Beckman S, Noguera R, Navarro S, et al. 2009 HIF-2alpha maintains an undifferentiated state in neural crest-like human neuroblastoma tumor-initiating cells. PNAS 106 16805-16810. (doi:10.1073/pnas.0904606106)

Toledo RA, Qin Y, Srikantan S, Morales NP, Li Q, Deng Y, Kim SW, Pereira MA, Toledo SP, Su X, et al. 2013 In vivo and in vitro oncogenic effects of HIF2A mutations in pheochromocytomas and paragangliomas. Endocrine-Related Cancer 20 349-359. (doi:10.1530/ ERC-13-0101)

Toyoda H, Hirayama J, Sugimoto Y, Uchida K, Ohishi K, Hirayama M \& Komada Y 2014 Polycythemia and paraganglioma with a novel somatic HIF2A mutation in a male. Pediatrics 133 e1787-e1791.

Witzigmann H, Loracher C, Geissler F, Wagner T, Tannapfel A, Uhlmann D, Caca K, Hauss J \& Hehl JA 2002 Neuroendocrine tumours of the duodenum. Clinical aspects, pathomorphology and therapy. Langenbecks Archives of Surgery 386 525-533. (doi:10.1007/s00423-001-0260-z)

Zhuang Z, Yang C, Lorenzo F, Merino M, Fojo T, Kebebew E, Popovic V, Stratakis CA, Prchal JT \& Pacak K 2012 Somatic HIF2A gain-offunction mutations in paraganglioma with polycythemia. New England Journal of Medicine 367 922-930. (doi:10.1056/ NEJMoa1205119)

Received in final form 3 April 2016

Accepted 18 April 2016

Accepted Preprint published online 29 April 2016
(C) 2016 Society for Endocrinology Printed in Great Britain
Published by Bioscientifica Ltd 